This accepted author manuscript is copyrighted and published by Elsevier. It is posted here by agreement between Elsevier and MTA. The definitive version of the text was subsequently published in [Journal of Molecular Liquids

Volume 245, November 2017, Pages 17-26 DOI 10.1016/j.molliq.2017.05.110]. Available under license CC-BY-NC-ND.

\title{
Dependence of the adsorption of halogenated methane derivatives at the ice surface on their chemical structure
}

\author{
Ildikó Sumi $^{\mathrm{a}}$, Sylvain Picaud ${ }^{\mathrm{b}}$, Pál Jedlovszky ${ }^{\mathrm{a}, \mathrm{c}, *}$
}

${ }^{a}$ Department of Chemistry, Eszterházy Károly University, Leányka u. 6, H-3300 Eger, Hungary

${ }^{\mathrm{b}}$ Institut UTINAM (CNRS UMR 6213), Université Bourgogne Franche-Comté, 16 route de Gray, F-25030 Besançon, France

${ }^{\mathrm{c}}$ MTA-BME Research Group of Technical Analytical Chemistry, Szt. Gellért tér 4, H-1111 Budapest, Hungary

Running title: Adsorption of halogenated methane derivatives at ice

*E-mail: jedlovszky.pal@uni-eszterhazy.hu, 


\section{Abstract:}

The adsorption of all the fluorinated and chlorinated methane derivatives as well as methane itself at the surface of $I_{h}$ ice is studied at the tropospheric temperature of $200 \mathrm{~K}$ by grand canonical Monte Carlo simulations. The general behaviour of the obtained isotherms is in good accordance with existing experimental data, giving us confidence in the models used. The shape of the adsorption isotherms is discussed in terms of the interplay of adhesive and cohesive interactions. It is found that in cases when the former of the two interactions is clearly the stronger one, multilayer adsorption occurs; when the latter interaction is the dominant one, no considerable adsorption is observed, while in cases when the two interactions are of roughly the same strength, the formation of a saturated monolayer occurs. The isotherms exhibit the Langmuir shape, at least up to the pressures where multilayer adsorption starts to occur, given that the cohesion acting between the adsorbate molecules is only moderately strong. Too strong cohesion, on the other hand, leads to the deviation of the isotherm from the Langmuir shape. While the strength of cohesion depends on the properties of the adsorbate molecules, that of adhesion is determined by hydrogen bond formation between the adsorbed molecules and surface waters. Our results show that while $\mathrm{CH}_{3} \mathrm{~F}$ and $\mathrm{CH}_{3} \mathrm{Cl}$ form several weak, $\mathrm{C}-\mathrm{H}$ donated hydrogen bonds with the surface molecules of the ice phase, the adsorbates containing more than one halogen atom form only one, though strong, O-H donated hydrogen bond with them.

Keywords: Adsorption; grand canonical Monte Carlo; ice surface; halogenated methane derivatives; atmospheric chemistry 


\section{Introduction}

Halogenated hydrocarbon molecules play several important roles in atmospheric chemistry, the better, more detailed understanding of which could be of essential importance concerning a number of environmental issues, such as the formation of the Antarctic ozone hole [1], or global warming due to the greenhouse effect [2]. Thus, stratospheric ozone destruction was found to be related to chemical reactions occurring between halogens released from ice particles with chlorofluorocarbon (CFC) molecules [3]. These latter molecules are long-living anthropogenic substances, and had been widely used as refrigerants until the end of the last century. With the Montreal Protocol having been signed in 1987, CFCs have been gradually replaced by hydrochlorofluorocarbons, and later by hydrofluorocarbons (HFCs) [4]. Although HFCs cause far less harm to the ozone layer than CFCs, they act as rather efficient greenhouse gases [2,5]. Furthermore, by increasing the temperature in the upper troposphere/lower stratosphere (UTLS) region, these HFC compounds, being otherwise harmless to the ozone layer, are expected to initiate catalytic reactions that will again lead to the destruction of the ozone layer [6]. Halogenated hydrocarbons are substances of low reactivity, particularly under tropospheric (i.e., low temperature low pressure) conditions, and hence they are long-living species in the atmosphere. As a consequence, their possible adsorption at the surface of water droplets and ice grains is of great importance concerning their atmospheric fate. Further, falling snow can scavenge these adsorbed molecules from the troposphere [7]. The presence of such atmospheric pollutants in the snow-covered part of the Earth (such as the polar regions), where they might undergo specific oxidative and photochemical reactions, also has an important influence on the overlaying atmosphere $[3,8,9]$.

The interaction of atmospheric trace gases [10-13], including halogenated compounds $[3,14]$, with the ice and water surface has extensively been investigated by various experimental methods in the past decades. However, in spite of the wealth of these kinds of studies, the simplest halocarbon species, namely halogenated methane derivatives, have received considerably less attention yet. Further, the majority of these studies were performed at considerably lower temperatures than what corresponds to tropospheric conditions (i.e., 200$220 \mathrm{~K}$ ). Thus, the interaction of $\mathrm{CCl}_{4}$ with the ice surface was studied by temperature programmed desorption (TPD) below $130 \mathrm{~K}$ [15-17]; the surface of ice nanocrystals was 
characterised using $\mathrm{CF}_{4}$ as a surface probe at $83 \mathrm{~K}$ [18], and the adsorption of $\mathrm{CF}_{4}$ on amorphous ice was investigated both by volumetric and Fourier transformation infrared spectroscopy (FTIR) measurements at $95 \mathrm{~K}$ [19]. All these studies led to the general conclusion that these tetrahedral molecules with the general formula of $\mathrm{CX}_{4}$ (X being a halogen atom) are rather weakly bound to the ice surface, and their adsorption depends on surface coverage, as the adsorption layer grows according to a three-dimensional clustering mechanism. Graham et al. studied the adsorption layer of $\mathrm{CHF}_{3}$ at the surface of $\mathrm{I}_{\mathrm{h}}$ ice by $\mathrm{He}$ scattering, and concluded that the $\mathrm{CHF}_{3}$ molecules form an ordered overlayer above the ice surface, facing their $\mathrm{F}$ atoms towards the gas phase [20]. Holmes and Sodeau performed infrared (IR) spectroscopy measurements, investigating the interaction of 23 different halogenated methane derivatives with the surface of amorphous ice at $12 \mathrm{~K}$ [21]. The main conclusion of their study was that this interaction always involves lone pair donation from a halogen to a dangling $\mathrm{H}$ atom [21]. Harper et al. studied the adsorption of $\mathrm{CH}_{3} \mathrm{Cl}$, along with that of methanol and the corresponding butyl species, at the surface of water at room temperature using vibrational sum frequency generation spectroscopy (SFG) [22]. Vysokikh et al. studied the interaction of partially chlorinated methane derivatives, adsorbed on a thin ice film, with ozone in a broad temperature range between $77 \mathrm{~K}$ and $292 \mathrm{~K}$. They excluded the possibility of the occurrence of a direct chemical reaction, at least at temperatures below $210 \mathrm{~K}$, showing that these compounds do not dissociate at the ice surface, and hence do not release chlorine in this temperature range [23]. The adsorption of $\mathrm{CHCl}_{3}$ at the surface of both crystalline and amorphous ice was studied by means of both x-ray photoelectron spectroscopy (PES) [24] and TPD [25] experiments. These studies led to the conclusion that there is a marked difference between monolayer and multilayer adsorption states of $\mathrm{CHCl}_{3}$ at the surface of crystalline ice, but no such difference is seen at amorphous ice [24,25]. Aoki et al. showed, using metastable impact electron spectroscopy that $\mathrm{CH}_{3} \mathrm{Cl}$ molecules adsorbed at the ice surface turn their $\mathrm{H}$ atoms towards the ice phase below $120 \mathrm{~K}$ [26]. It was also shown that both $\mathrm{CHCl}_{3}$ [24,25] and $\mathrm{CH}_{3} \mathrm{Cl}$ [27] remain immobile at the ice surface in the entire temperature range below desorption due to their interaction with the surface water molecules [24,25,27], and that the interaction of all chlorinated methane derivatives with water involves the water $\mathrm{O}$ atom [28]. 
Experimental studies can be well complemented by computer simulation investigations in many respects, as the simulation of a suitable model of the system to be studied allows the system to be seen at atomistic resolution in three dimensions [29]. Given that the chosen model is successful in reproducing the experimentally known properties of the system of interest, computer simulations can provide detailed direct insights into the structure and dynamics of the studied system on the molecular level. These insights could not have been achieved solely by any experimental method. The interaction of halogenated methane derivatives with water and ice was the subject of several computer simulation investigations. In one of the first of such studies, we performed molecular dynamics (MD) simulations of $\mathrm{CHCl}_{3}$ at the (0001) surface of $I_{h}$ ice at various surface coverages [30]. Later, we calculated the solvation free energy profile of 15 molecules, including $\mathrm{CH}_{2} \mathrm{~F}_{2}, \mathrm{CH}_{2} \mathrm{Cl}_{2}$, and $\mathrm{CHCl}_{3}$, at the surface of both water and ice [31]. Recently, Habartová et al. determined this profile at the water-vapour interface for all partially chlorinated and brominated methane derivatives [32]. They also studied the properties of the isolated $\mathrm{CH}_{n} \mathrm{Cl}_{4-n}$ and $\mathrm{CH}_{n} \mathrm{Br}_{4-n}$ molecules ( $n$ being between 1 and 3) at the ice surface [33]. Complementing their SFG study, Harper et al. also performed MD simulations of $\mathrm{CH}_{3} \mathrm{Cl}$ at the vicinity of the free water surface [22].

Recently, we performed a set of grand canonical Monte Carlo (GCMC) [29,34] simulations investigating the adsorption of all the fluorinated and chlorinated methane derivatives at the (0001) surface of $I_{h}$ ice [35-37]. In these studies, we compared the performance of various potential models, determined the adsorption isotherm, and characterised the orientation and energetics of the adsorbed molecules for each of these species [35-37]. Based on these studies, here we attempt to compare the adsorption behaviour of these molecules with each other, and address the question of how the adsorption properties depend on the type and number of halogen atoms present in the molecule. Relationships between the adsorption and physical properties of these compounds (i.e., molar mass, dipole moment, dielectric constant, boiling and critical point) are also investigated. These properties of the adsorbates considered are collected in Table 1.

The rest of the paper is organized as follows. The computations performed, including the GCMC simulations and calculation of the adsorption isotherms are detailed in sec. 2. The adsorption properties of the different compounds are compared and discussed in sec. 3. Finally, in sec. 4 , the most important conclusions of this study are summarised. 


\section{Computational details}

\subsection{Grand canonical Monte Carlo simulations}

The simulations performed to study the adsorption of the various fluorinated and chlorinated molecules have been described in detail in our previous publications [35-37], therefore, they are only briefly reviewed here. A set of GCMC simulations were performed for all nine molecules characterised by the general formula $\mathrm{CH}_{n} \mathrm{X}_{4-n}$, where $0 \leq n \leq 4$ and $\mathrm{X}$ stands either for $\mathrm{F}$ or $\mathrm{Cl}$, at the free (0001) surface of $\mathrm{I}_{\mathrm{h}}$ ice at the tropospheric temperature $T=200 \mathrm{~K}$. In these simulations, the chemical potential of the adsorbate, $\mu$, was systematically varied from values characteristic to a practically empty surface to those corresponding to the condensed phase of the adsorbate, and the mean number of the adsorbed molecules, $\langle N\rangle$, was determined as a function of $\mu$. The rectangular basic simulation box hosted 2880 water molecules, arranged in 18 molecular layers according to the geometry of $\mathrm{I}_{\mathrm{h}}$ ice. The $X, Y$, and $Z$ edges of the basic box were $100 \AA, 38.891 \AA$, and $35.926 \AA$ long, $X$ being the axis perpendicular to the interface. The lengths of the $Y$ and $Z$ edges were set in accordance with the periodicity of the ice crystal.

Water molecules were modelled by the 5-site TIP5P potential, which, apart from the three atomic sites, also includes two non-atomic charged sites in the direction of the lone pairs of the $\mathrm{O}$ atom [41]. The choice of this water model was dictated by the previous finding that it reproduces the melting temperature of $I_{h}$ ice within a few Kelvin [42,43]. All molecules with the general formula of $\mathrm{CH}_{n} \mathrm{~F}_{4-n}$ (including $\mathrm{CH}_{4}$ ), with the exception of $\mathrm{CH}_{2} \mathrm{~F}_{2}$, were described by the potential model family proposed by Palmer and Anchell (PA) [44]. We showed that the PA model of $\mathrm{CH}_{2} \mathrm{~F}_{2}$ seriously overestimates the strength of the intermolecular interaction (i.e., cohesion) [36]. Therefore, for $\mathrm{CH}_{2} \mathrm{~F}_{2}$ the potential model Jedlovszky and Mezei (JM) [45] was used. This model was shown to provide reliable results at $200 \mathrm{~K}[35,45] . \mathrm{CH}_{3} \mathrm{Cl}$ was modelled by the general AMBER force field (GAFF) [46], using the charge distribution proposed by Habartová et al. [32]. $\mathrm{CH}_{2} \mathrm{Cl}_{2}$ and $\mathrm{CHCl}_{3}$ molecules were described by the potential models proposed by Ferrario and Evans [47], using the geometry parameters of Kneller and Geiger [48], and by Dietz and Heinzinger [49], respectively, while in describing $\mathrm{CCl}_{4}$ the OPLS potential model [50] was used. It was also shown that the OPLS model of $\mathrm{CH}_{3} \mathrm{Cl}$ [51] severely 
underestimates the cohesion of the molecules [37], while the OPLS model of $\mathrm{CHCl}_{3}$ [52] provides compatible results with that of Dietz and Heinzinger [49] for our purpose [37]. All potential models considered are rigid and pairwise additive; the interaction of a molecule pair is given as the sum of the Lennard-Jones and Coulomb contributions of all pairs of their respective sites. According to the original parametrisation of the TIP5P water model [41], all interactions have been truncated to zero beyond the molecule centre-based cut-off distance of $12.5 \AA$ (the $\mathrm{O}$ and $\mathrm{C}$ atom being regarded as the centre of the water and adsorbate molecules, respectively).

The simulations were performed using the program MMC [53]. In the simulations, particle displacement and insertion/deletion attempts were done in alternating order. In a particle displacement step, a randomly chosen molecule was randomly translated and rotated by no more than $0.25 \AA$ and $15^{\circ}$, respectively. In an insertion/deletion attempt, either an existing adsorbate molecule was removed from, or a new adsorbate molecule was added to the system. Insertion and deletion attempts were performed with equal probabilities, using the cavity biased scheme of Mezei [54,55]. At least $10 \%$ of the particle displacement and $0.1 \%$ of the insertion/deletion attempts turned out to be successful in every case. The systems were equilibrated by performing at least $4 \times 10^{8}$ Monte Carlo steps. The number of adsorbed molecules at the given chemical potential value was then averaged over $10^{8}$ equilibrium configurations. Detailed analyses were performed at selected chemical potential values for each system, for this purpose 2500 sample configurations were saved from a $5 \times 10^{8}$ Monte Carlo steps long trajectory in every case. Finally, all results were also averaged over the two ice surfaces present in the basic simulation box.

\subsection{Calculation of the adsorption isotherm}

The adsorption isotherm is defined, in general, as the surface excess of the adsorbate, $\Gamma$, as a function of its bulk phase concentration. In cases when the adsorption occurs at the solidgas or solid-vapour interface, the isotherm is conveniently provided in the form of surface density vs. pressure $(p)$. The use of this form requires that (i) the gas phase can be treated as an ideal gas, and hence the pressure is proportional to the concentration, and (ii) the bulk gas/vapour phase concentration of the adsorbate is small enough to assume that the surface excess is equal to the surface density. In a computer simulation, this latter condition requires 
the gas phase of the simulation box to be practically empty. While the first of these conditions was satisfied in all of our simulations, the second one was not satisfied when the adsorbate was $\mathrm{CH}_{4}$ and $\mathrm{CF}_{4}$. In these cases, the gas/vapour phase of the basic box was never completely empty; there was always a noticeable fraction of the adsorbate molecules that were located in their bulk phase [36]. In cases when the second of the above conditions is also satisfied, $\Gamma$ can simply be calculated as

$$
\Gamma=\frac{<N>}{2 Y Z}
$$

where the factor of two in the denominator accounts for the two interfaces present in the basic box. Otherwise, when converting the $\langle N\rangle$ vs. $\mu$ data to the $\Gamma$ vs. $p$ adsorption isotherm, $\Gamma$ has to be understood as the surface excess $[54,55]$, i.e.,

$$
\Gamma=\int_{-\infty}^{X_{\mathrm{G}}} \rho(X) \mathrm{d} X+\int_{X_{\mathrm{G}}}^{\infty}\left(\rho(X)-\rho_{\mathrm{gas}}\right) \mathrm{d} X,
$$

where $\rho(X)$ is the molecular number density profile, $\rho_{\mathrm{gas}}$ is the density in the bulk gas phase, and $X_{\mathrm{G}}$ is the position of the Gibbs dividing surface along the surface normal axis, $X$. In calculating $\Gamma$ from our simulations, the lower boundary of the first integral was set to zero (i.e., the middle of the ice phase), the upper boundary of the second integral was set to $X / 2$ (i.e., middle of the gas phase), and the value of $X_{\mathrm{G}}$ was determined from the condition

$$
\int_{0}^{X_{\mathrm{G}}} \rho(X) \mathrm{d} X=\int_{X_{\mathrm{G}}}^{X / 2}\left(\rho_{\text {gas }}-\rho(X)\right) \mathrm{d} X,
$$

i.e., that no adsorption is possible if the density of the gas phase is sufficiently high. To obtain the value of $X_{\mathrm{G}}$ from eq. 3 the density profile resulted from the simulation corresponding to the highest $\mu$ value considered (i.e., when the adsorbate molecules formed a liquid or dense gas phase) was used.

In the simulations, in particular, when the gas phase is practically empty, the pressure (or the gas phase concentration) can only be determined with far too large error bars. Instead of 
the pressure of the system, however, the relative pressure, $p_{\text {rel }}$, i.e., the pressure normalized by that of the saturated vapour, $p_{0}$, can easily be determined in the simulations as [56]

$$
p_{\text {rel }}=\frac{p}{p_{0}}=\frac{\exp (\beta \mu)}{\exp \left(\beta \mu_{0}\right)}
$$

where $\beta=1 / k_{\mathrm{B}} T, k_{\mathrm{B}}$ is the Boltzmann constant, and $\mu_{0}$ is the adsorbate chemical potential corresponding to the point of condensation. The value of $\mu_{0}$ can usually be easily determined from the $N$ vs. $\mu$ data, since at the point of condensation the number of adsorbate molecules present in the basic box exhibits a sudden jump (as the bulk adsorbate phase becomes liquid from vapour). In the case of $\mathrm{CH}_{2} \mathrm{~F}_{2}$, which shows strong multilayer adsorption, this determination of $\mu_{0}$ might be subject to systematic error, since the situations when the adsorption layer becomes as wide as the vapour phase in the basic box, and when it becomes infinitely wide (i.e., condensation occurs) cannot be distinguished. Therefore, in this case the point of condensation was determined by performing a new set of GCMC simulations of neat $\mathrm{CH}_{2} \mathrm{~F}_{2}$, without the presence of the ice phase, where liquid-vapour transition occurs abruptly, without being preceded by the occurrence of an adsorption layer [35]. In the case of $\mathrm{CH}_{4}$, however, it turned out that the adsorbate is already above its critical point at the simulation temperature [36]. In the lack of the point of condensation, when calculating $p_{\text {rel }}$ through eq. 4 , $\mu_{0}$ refers to the chemical potential corresponding to the so-called Widom line, i.e., the supercritical extension of the vapour-liquid coexisting curve, connecting the points on the $p-T$ plane at which the thermodynamic response functions, such as the isothermal compressibility, go through a finite maximum $[57,58]$. The value of $\mu_{0}$ can easily be estimated by performing a simple numerical derivation of the $\langle N\rangle$ vs. $\mu$ data. Finally, it should be noted that, in the case of subcritical adsorbates, $\mu_{0}$ and $p_{0}$ correspond to the point of condensation, and hence $p_{\text {rel }}$ (i.e., the vapour pressure relative to that of the saturated vapour) cannot exceed unity, but in the case of supercritical adsorbates, the $p_{\text {rel }}$ values above 1 are also physically meaningful, as they simply correspond to the state of a dense gas. 


\section{Results and discussion}

To make our results comparable for the different adsorbates, in the following analyses (i.e., calculation of mean interaction energies and orientational statistics of the adsorbates) we only consider the two extreme situations when the adsorbate molecules form an adsorption monolayer of very low surface coverage, and when they form a condensed phase. Once the point of condensation is determined, state points corresponding to the latter situation can easily be chosen. In these state points we only considered the adsorbate molecules that are in a direct contact with the ice phase (as defined through the first minimum position of the adsorbate density profile) in our analyses. Choosing appropriate state points corresponding to the first situation, on the other hand, is less straightforward, as even in cases when, on average, less than one adsorbate molecule is situated at an ice surface, there are snapshots in which the lateral interaction between the adsorbate molecules is not zero. Further, when too few adsorbate molecules are considered, the statistical uncertainty of the obtained results becomes rather high. As a compromise between the approximation of the idealized situation of an infinitely dilute adsorption monolayer and a reasonable statistical sampling, we have chosen, for all adsorbates, state points in which, on average, less than 2 molecules are adsorbed at each of the two ice surfaces in the basic box, to also investigate the first of the above two extreme situations.

\subsection{Relation of the adsorption isotherms with the adhesive and cohesive interactions}

The $\langle N\rangle$ vs. $\mu$ data obtained for the nine adsorbates considered are shown and compared in Figure 1. As is seen, with the exception of $\mathrm{CH}_{4}$, all data sets exhibit a sudden jump at a certain $\mu$ value. This chemical potential, denoted here as $\mu_{0}$ and collected in Table 2 , corresponds to the condensation of the adsorbate. $\mathrm{CH}_{4}$ is already above its (experimental) critical point at the simulation temperature (see Table 1), which is well captured by the potential used: the mean number of the $\mathrm{CH}_{4}$ molecules in the basic box, $\langle N\rangle$, changes continuously with $\mu$, without showing any sign of a first order phase transition. The steepness of the liquid branch of the $\langle N\rangle$ vs. $\mu$ data reflects the vicinity of the critical point (as the liquid phase becomes less dense, and hence more compressible upon approaching the critical point). 
Thus, this steepness is considerably larger for the fluorinated than for the chlorinated molecules, in accordance with the fact that the critical temperature, $T_{\text {crit }}$, of the former molecules is scattered between about $230 \mathrm{~K}$ and $350 \mathrm{~K}$, while that of the latter ones is distributed between $415 \mathrm{~K}$ and $560 \mathrm{~K}$ (see Table 1). Further, among the chlorinated molecules the $T_{\text {crit }}$ value of $\mathrm{CH}_{3} \mathrm{Cl}$ is at least $100 \mathrm{~K}$ lower than that of the other ones, which is also reflected in the noticeably larger steepness of the liquid branch of the $\mathrm{CH}_{3} \mathrm{Cl}$ data than that of the other chlorinated molecules. Finally, the high density part of the $\langle N\rangle$ vs. $\mu$ data of $\mathrm{CH}_{4}$ (being already above its critical point) is also clearly steeper than the liquid branch of any of the subcritical adsorbates.

It is seen that, in general, the point of condensation of the fluorinated compounds occurs at higher $\mu$ values than that of the chlorinated molecules. The simulated $\mu_{0}$ values, corresponding to the point of condensation, correlate well with the experimental boiling point of these compounds at atmospheric pressure (see the inset of Figure 2.a), providing us with further confidence in the potential models used. The value of $\mu_{0}$ primarily characterises the cohesion between the adsorbate molecules. To demonstrate this, we have calculated the average interaction energy of an adsorbate molecule, located in the first layer of its phase (i.e., in contact with the ice surface), with all the other adsorbate molecules in the system, right above the point of condensation. This energy value, denoted here as $\left\langle U_{\text {cond }}^{\text {lat }}\right\rangle$, is a direct measure of the cohesion acting in the condensed phase of the adsorbate, as experienced by a molecule located at the boundary of its phase. The values of $\left\langle U_{\text {cond }}^{\text {lat }}\right\rangle$ are also included in Table 2. As shown in Figure 2.a, these values exhibit a clear correlation with the values of $\mu_{0}$, and thus also with the experimental boiling points of the corresponding adsorbates, confirming that the value of $\mu_{0}$ is indeed related to the cohesion among the adsorbate molecules.

The adhesion, i.e., the attraction between the ice phase and the adsorbed molecules is, on the other hand, characterised by the $\mu$ value at which the $\langle N\rangle$ vs. $\mu$ data becomes noticeably different from zero. This is not a well defined point, as $\langle N\rangle$ changes gradually, following an exponential increase with $\mu$ at low enough surface coverages. For the purpose of the present analysis, here we define this point, denoted as $\mu_{\text {start }}$, as the $\mu$ value at which $\langle N\rangle$ reaches $0.1 \%$ of its condensed phase value. The $\mu_{\text {start }}$ values corresponding to the various adsorbates considered are also collected in Table 2 . To demonstrate that the value of $\mu_{\text {start }}$ is indeed related 
to the adhesion of the adsorbate molecules, we also calculated the mean interaction energy of an adsorbate molecule with the ice phase at very low surface coverage, $\left\langle U_{\text {low }}^{\text {ice }}\right\rangle$, which can be regarded as a direct measure of this adhesion. The values obtained for $\left\langle U_{\text {low }}^{\text {ice }}\right\rangle$ for the nine adsorbates considered are also included in Table 2. It should be noted that the value of $<U_{\text {low }}^{\text {ice }}>$ can be regarded as a good estimate of the heat of adsorption at infinitely low surface coverage, a quantity that is experimentally relatively easily accessible. Although we are not aware of any experimental study in which this value is reported for any of the adsorbates studied here, their future measurements can provide an additional test of validity of the present results. In Figure 2.b the $\left\langle U_{\text {low }}^{\text {ice }}\right\rangle$ values are plotted against $\mu_{\text {start }}$ for all the nine adsorbates considered. As is clearly seen from the figure, the two values are indeed in a strong correlation with each other, confirming that, unlike $\mu_{0}, \mu_{\text {start }}$ is indeed related to the adhesion rather than to the cohesion of the adsorbate molecules.

The adsorption isotherms of the nine adsorbates considered are shown and compared in Figure 3 in their $\Gamma$ vs. $p_{\text {rel }}$ form. The values of $\mu_{\text {start }}$ and $\mu_{0}$, determined by the adhesion and the cohesion of the adsorbate molecules, respectively, are transformed to the two endpoints of the $\Gamma\left(p_{\text {rel }}\right)$ isotherm (i.e., to $p_{\text {rel }} \approx 0$ and $p_{\text {rel }}=1$, respectively). The shape of the isotherm in the entire intermediate $p_{\text {rel }}$ range is determined by a delicate interplay of the adhesive and cohesive interactions. Thus, adsorbates for which the ratio of $\left\langle U_{\text {low }}^{\text {ice }}\right\rangle$ and $\left\langle U_{\text {cond }}^{\text {lat }}\right\rangle$, i.e., the energy values that are characteristic of adhesion and cohesion, respectively, is well above unity (i.e., $\mathrm{CH}_{3} \mathrm{~F}$ and $\mathrm{CH}_{2} \mathrm{~F}_{2}$ ) exhibit clear multilayer adsorption. Correspondingly, for these adsorbates the value of $\left(\mu_{0}-\mu_{\text {start }}\right)$ exceeds $15 \mathrm{~kJ} / \mathrm{mol}$. Adsorbates having a $\left\langle U_{\text {low }}^{\text {ice }}\right\rangle \mid\left\langle U_{\text {cond }}^{\text {lat }}\right\rangle$ ratio around unity, and a $\left(\mu_{0}-\mu_{\text {start }}\right)$ value around $13-14 \mathrm{~kJ} / \mathrm{mol}$ (i.e., $\mathrm{CHF}_{3}$ and $\mathrm{CH}_{3} \mathrm{Cl}$ ) exhibit considerable adsorption, corresponding more or less to the formation of a saturated adsorption monolayer, with traces of multilayer adsorption in the case of $\mathrm{CHF}_{3}$ (for which the $\left\langle U_{\text {low }}^{\text {ice }}\right\rangle \mid\left\langle U_{\text {cond }}^{\text {lat }}\right\rangle$ ratio slightly exceeds unity). Finally, adsorbates having a $\left\langle U_{\text {low }}^{\text {ice }}\right\rangle \mid\left\langle U_{\text {cond }}^{\text {lat }}\right\rangle$ ratio well below unity, and a $\left(\mu_{0}-\mu_{\text {start }}\right)$ value clearly below $10 \mathrm{~kJ} / \mathrm{mol}$ do not show considerable adsorption; their 
condensation occurs in the situation when they only form a highly unsaturated monolayer at the ice surface.

Finally, it is interesting to note that while the $\Gamma\left(p_{\text {rel }}\right)$ adsorption isotherms of $\mathrm{CH}_{3} \mathrm{~F}$, $\mathrm{CH}_{2} \mathrm{~F}_{2}$, and $\mathrm{CHF}_{3}$ can all be very well fitted by the Langmuir isotherm $[59,60]$ up to a certain $p_{\text {rel }}$ value (corresponding to the point at which the second molecular layer starts to build up), as shown also in Figure 3, the isotherm of $\mathrm{CH}_{3} \mathrm{Cl}$ cannot be fitted by the Langmuir isotherm even in the range of very small $p_{\text {rel }}$ values, although this adsorbate does not show multilayer adsorption up to $p_{\text {rel }}=1$. To understand this finding, one has to consider that the Langmuir isotherm assumes no lateral interaction between the adsorbate molecules. Although some lateral interaction is always present in a real adsorption layer, up to a point it does not distort

the Langmuir shape of the isotherm. However, as seen from Table 2, the value of $\left\langle U_{\text {cond }}^{\text {lat }}\right\rangle$, characterising the strength of the lateral interactions (i.e., cohesion) is 1.5-2 times larger (in magnitude) for $\mathrm{CH}_{3} \mathrm{Cl}$ than for the three partially fluorinated molecules. This cohesion acting between the $\mathrm{CH}_{3} \mathrm{Cl}$ molecules turns out to be already large enough to give a non-Langmuir character of the adsorption isotherm.

\subsection{Orientation of the adsorbed molecules}

In the previous sub-section, we have related the properties of the adsorption isotherm to the interplay of the adhesive and cohesive forces acting in the system. It is also clear that the strength of the cohesive interaction is primarily related to molecular properties of the adsorbate, such as the molecular mass and dipole moment. To investigate the origin of the strength of the adhesive interaction, here we analyse the orientation of the adsorbed molecules relative to the ice surface. Again, we consider the two extreme situations, i.e., the presence of an (almost) infinitely unsaturated adsorption monolayer, and that of the condensed phase of the adsorbate, and take only those adsorbate molecules into account in the orientational analysis, which are in a direct contact with the ice phase.

The description of the orientation of a rigid body (in our case, an adsorbate molecule) relative to an external direction (in our case, the surface normal) can, in general, be done by using two independent orientational variables. Therefore, describing the statistics of such orientations requires the calculation of the bivariate joint distribution of these variables [61,62]. We demonstrated that the angular polar coordinates, $\vartheta$ and $\phi$, of the surface normal vector in a 
local Cartesian frame fixed to the individual molecules are a sufficient choice of such an orientational variable pair $[61,62]$. It should be noted that $\vartheta$ is the angle of two general spatial vectors (i.e., the surface normal vector, $\underline{X}$, pointing, by our convention, from the ice to the vapour phase, and axis $z$ of the local frame), but $\phi$ is an angle of two vectors (i.e., the projection of $\underline{X}$ to the $x y$ plane of the local frame and axis $x$ of this frame) restricted, by definition, to lay in a given plane (i.e., the $x y$ plane of the local frame). Therefore, the points of the bivariate distribution correspond to the same density of the orientations (and, hence, uncorrelated orientations with the interface results in a uniform distribution) only if $\cos \vartheta$ and $\phi$ are chosen to be the independent orientational variables [61,62].

The adsorbates corresponding to the general formula $\mathrm{CX}_{4}$ are of almost spherical shape, and, due to their lack of a permanent dipole moment, have only rather weak interaction with the ice phase. Therefore, we limit our orientational analysis to the partially halogenated methane derivatives, corresponding to the general formulae of $\mathrm{CH}_{2} \mathrm{X}_{2}$ (where $\mathrm{X}$ stands for a halogen atom) or $\mathrm{CX}_{3} \mathrm{Y}$ (where either $\mathrm{X}$ or $\mathrm{Y}$ stands for a halogen, while the other for the $\mathrm{H}$ atom). The local Cartesian frame fixed to the adsorbate molecules is defined in the following way. For molecules of the general formula of $\mathrm{CX}_{3} \mathrm{Y}$, axis $z$ is the main symmetry axis of the molecule, pointing from atom $\mathrm{Y}$ (i.e., $\mathrm{H}$ for $\mathrm{CHF}_{3}$ and $\mathrm{CHCl}_{3}$, and the halogen for $\mathrm{CH}_{3} \mathrm{~F}$ and $\mathrm{CH}_{3} \mathrm{Cl}$ ) to the $\mathrm{C}$ atom. Axis $x$ is then chosen in such a way that the projection of one of the $\mathrm{X}$ atoms (i.e., $\mathrm{H}$ for $\mathrm{CH}_{3} \mathrm{~F}$ and $\mathrm{CH}_{3} \mathrm{Cl}$, halogen for $\mathrm{CHF}_{3}$ and $\mathrm{CHCl}_{3}$ ) to the $x y$ plane is located along this axis, at its positive side, while axis $y$ is perpendicular to the other two. $\mathrm{For} \mathrm{CH}_{2} \mathrm{~F}_{2}$ and $\mathrm{CH}_{2} \mathrm{Cl}_{2}$, axis $z$ again coincides with the main symmetry axis of the molecule, pointing from the hydrogen towards the halogen atoms, while axes $x$ and $y$ are parallel with the lines joining the two $\mathrm{H}$, and the two halogen atoms, respectively. It should finally be noted that, due to the $\mathrm{C}_{3 \mathrm{v}}$ symmetry of the $\mathrm{CX}_{3} \mathrm{Y}$, and $\mathrm{C}_{2 \mathrm{v}}$ symmetry of the $\mathrm{CH}_{2} \mathrm{X}_{2}$ molecules, these frames can always be chosen in such a way that $\phi$ does not exceed $60^{\circ}$ (for $\mathrm{CX}_{3} \mathrm{Y}$ ) and $90^{\circ}$ (for $\mathrm{CH}_{2} \mathrm{X}_{2}$ ). The definition of these local frames and that of the polar angles $\vartheta$ and $\phi$ for the $\mathrm{CX}_{3} \mathrm{Y}$ and $\mathrm{CH}_{2} \mathrm{X}_{2}$ type adsorbates is illustrated in panels a and $\mathrm{b}$ of Figure 4, respectively.

The $P(\cos \vartheta, \phi)$ orientational maps obtained for the $\mathrm{CX}_{3} \mathrm{Y}$ and $\mathrm{CH}_{2} \mathrm{X}_{2}$ adsorbates are shown in Figures 5 and 6, respectively. As is seen from these figures, neither the type of halogen atom nor the surface coverage has a real influence on the orientational preferences of 
the adsorbate molecules in any case, although with increasing surface coverage the preferences for the same orientations become noticeably weaker.

The orientational maps of $\mathrm{CH}_{3} \mathrm{~F}$ and $\mathrm{CH}_{3} \mathrm{Cl}$ have their maximum at $\cos \vartheta=-1$, extending along the entire $\phi$ range from $0^{\circ}$ to $60^{\circ}$. It should be noted that, according to the definition of the local Cartesian frame (see Figure 4.a), in the case of $\cos \vartheta=-1$ the interface normal vector coincides with axis $z$ of this local frame, its projection to the $x y$ plane becomes a single point, and hence angle $\phi$ loses its meaning. In other words, all points of the $P(\cos \vartheta, \phi)$ map along the $\cos \vartheta=-1$ line correspond to the same orientation, in which the halogen atom sticks straight away from, while the three $\mathrm{C}-\mathrm{H}$ bonds point flatly towards the ice surface. This preferred orientation is also illustrated in Figure 5.

The $\mathrm{CHF}_{3}$ and $\mathrm{CHCl}_{3}$ molecules exhibit a dual orientational preference, as evidenced by the presence of two distinct maxima of the $P(\cos \vartheta, \phi)$ orientational maps. Both orientations correspond to slightly negative $\cos \vartheta$ values, indicating that the $\mathrm{C}$ - $\mathrm{H}$ bond lays almost parallel with the ice surface, tilting slightly away from it. In the first of these preferred orientations, marked here as $\mathrm{A}$, the value of $\phi$ is around $60^{\circ}$, while in the second one, marked here as $\mathrm{B}$, its value is close to $0^{\circ}$. Thus, in orientation $A$, one of the halogen atoms points as straight towards, while in orientation B as straight away from the ice phase as possible, within the constraint set by the alignment of the $\mathrm{C}-\mathrm{H}$ axis. Orientations $\mathrm{A}$ and $\mathrm{B}$ of these molecules are also illustrated in Figure 5.

The $\mathrm{CH}_{2} \mathrm{X}_{2}$ molecules also have a dual orientational preference (see Figure 6). The first of these preferred orientations, denoted here by $\mathrm{A}$, corresponds to $\cos \vartheta=-0.3$ and $\phi=90^{\circ}$. In this orientation, one of the halogen atoms points straight towards the ice phase, while the other halogen and the two $\mathrm{H}$ atoms point flatly away from it. The other orientation, denoted by B, corresponds to $\cos \vartheta=-1$ and $\phi=0^{\circ}$, i.e., the main symmetry axis of the molecule is perpendicular to the surface, oriented in such a way that the two halogen atoms point towards, while the two hydrogen atoms away from the ice phase. These preferred orientations are also illustrated in Figure 6.

In understanding the origin of the adhesive interaction between the halogenated adsorbate molecules and the ice surface, the possibility of the formation of hydrogen bonds between them has to be considered. Water molecules at the ice surface have four clear, distinct 
orientational preferences [63] (see the inset of Figure 79). These orientational preferences are such that the adsorbed halogenated methane derivatives can, in principle, form several hydrogen bonds with the surface waters in all of their preferred orientations.

In their preferred orientation, the $\mathrm{CH}_{3} \mathrm{~F}$ and $\mathrm{CH}_{3} \mathrm{Cl}$ turn their three $\mathrm{H}$ atoms towards the ice surface, and can thus form up to three weak, $\mathrm{C}-\mathrm{H}$ donated hydrogen bonds with the $\mathrm{O}$ atoms of the surface water molecules. Possible hydrogen bonds of this kind, in which both molecules are in one of their preferred alignments, are illustrated in Figure 7. Similar hydrogen bond formation was observed in a recent ab initio study of the water $-\mathrm{CH}_{3} \mathrm{~F}$ and water- $\mathrm{CH}_{3} \mathrm{Cl}$ dimers [64]. Considering the obtained $\left\langle U_{\text {low }}^{\text {ice }}\right\rangle$ values (see Table 2) and also the fact that the average energy of such a $\mathrm{C}-\mathrm{H}$ donated hydrogen bond is around $-10--12 \mathrm{~kJ} / \mathrm{mol}$ [65], we can conclude that while the majority of the adsorbed $\mathrm{CH}_{3} \mathrm{Cl}$ molecules form three such weak $\mathrm{H}$ bonds with the surface waters, a non-negligible fraction of the $\mathrm{CH}_{3} \mathrm{~F}$ molecules form fewer (presumably two) such hydrogen bonds, at least at very low surface coverages.

In their preferred orientation $\mathrm{A}$, the $\mathrm{CHF}_{3}$ and $\mathrm{CHCl}_{3}$ molecules can, in principle, form up to three strong, $\mathrm{O}-\mathrm{H}$ donated hydrogen bonds with the dangling $\mathrm{H}$ atoms of the surface water molecules (one in each of the three lone pair directions of the halogen atom turned towards the ice surface). Similarly, in their orientation B, these molecules can form up to two such H-bonds (both of the downward oriented halogen atoms have one lone pair direction pointing towards the ice phase). Such possible H-bonding alignments, in which both molecules are in one of their preferred orientations, are illustrated in Figure 7. Again, formation of this type of hydrogen bond was also observed in an ab initio study of the water- $\mathrm{CHF}_{3}$ and water$\mathrm{CHCl}_{3}$ dimers [64], although in different relative arrangements of the molecules. However, one cannot expect matching relative orientations when the halomethane molecule interacts with a single, isolated water molecule and with the surface of ice, where a large number of water molecules are arranged in a strongly oriented way. Considering that the $\left\langle U_{\text {low }}^{\text {ice }}\right\rangle$ value of $\mathrm{CHF}_{3}$ and $\mathrm{CHCl}_{3}$ is around $-30 \mathrm{~kJ} / \mathrm{mol}$ and $-20 \mathrm{~kJ} / \mathrm{mol}$, respectively, and that the energy of a strong, O-H donated hydrogen bond typically falls between $-20 \mathrm{~kJ} / \mathrm{mol}$ and $-25 \mathrm{~kJ} / \mathrm{mol}$, it is clear that these molecules are stabilised at the ice surface by only one of such H-bonds (being even rather weak in the case of $\mathrm{CHCl}_{3}$ ), even at very low surface coverages. 
Finally, in their preferred orientations $\mathrm{A}$ and $\mathrm{B}$, the $\mathrm{CH}_{2} \mathrm{X}_{2}$ type molecules can also form three and two $\mathrm{O}-\mathrm{H}$ donated hydrogen bonds, respectively, with the surface water molecules. (In the first case, one H-bond can be formed in all three lone pair directions of the downward oriented halogen atom, while in the second case both of the downward oriented halogen atoms have one lone pair pointing towards the ice phase, in the direction of which these halogen atoms can accept such a hydrogen bond). Examples for such $\mathrm{H}$-bonding arrangements, in which both the $\mathrm{CH}_{2} \mathrm{X}_{2}$ adsorbate and the surface water molecule are aligned in one of their preferred orientations, are also illustrated in Figure 7. However, considering that the value of $\left\langle U_{\text {low }}^{\text {ice }}\right\rangle$ is again around only $-25 \mathrm{~kJ} / \mathrm{mol}$ and $-20 \mathrm{~kJ} / \mathrm{mol}$ for $\mathrm{CH}_{2} \mathrm{~F}_{2}$ and $\mathrm{CH}_{2} \mathrm{Cl}_{2}$, respectively, we can conclude that, similarly to $\mathrm{CHF}_{3}$ and $\mathrm{CHCl}_{3}$, these molecules also do not form more than one hydrogen bonds with the surface water molecules.

\section{Summary and conclusions}

The adsorption of all the fluorinated and chlorinated methane derivative molecules as well as of methane itself has been analysed and compared at the surface of $I_{h}$ ice under tropospheric conditions by GCMC computer simulations. We found that the behaviour of the obtained isotherms is in reasonable agreement with what can be expected from existing experimental data. Thus, the steepness of the liquid branch of the $\langle N\rangle$ vs. $\mu$ data shows strong correlation with the distance of the simulation temperature of $200 \mathrm{~K}$ from the experimental critical point for all the adsorbates studied. Further, $\mathrm{CH}_{4}$ is found to be already in a supercritical state at $200 \mathrm{~K}$, again in accordance with the experimental data [39]. Also, the simulated $\mu_{0}$ values, corresponding to the point of condensation of the adsorbates simulated, show a strong correlation with the experimental boiling points of these substances.

We found that the behaviour of the adsorption isotherms is determined by the interplay of the adhesive and cohesive interaction. As far as the $\langle N\rangle$ vs. $\mu$ data are concerned, the former interaction can be characterised by the (loosely defined) chemical potential value at which $\langle N\rangle$ becomes noticeably different from zero, $\mu_{\text {start }}$, while the latter can be characterised by the chemical potential at which condensation of the adsorbate occurs, $\mu_{0}$. When converting the $\langle N\rangle$ vs. $\mu$ data to the adsorption isotherm in its $\Gamma\left(p_{\text {rel }}\right)$ form, these chemical potential 
values are transformed to the two endpoints of the isotherm, i.e., $p_{\text {rel }} \approx 0$ and $p_{\text {rel }}=1$, respectively. The behaviour of the isotherm between these two endpoints is mainly determined by the relationship between the strengths of the cohesive and adhesive interactions (or, equivalently, by the distance of $\mu_{0}$ and $\mu_{\text {start }}$ ). Thus, in cases when adhesion is considerably stronger than cohesion (i.e., for $\mathrm{CH}_{3} \mathrm{~F}$ and $\mathrm{CH}_{2} \mathrm{~F}_{2}$ ), clear multilayer adsorption occurs. When these two interactions are of roughly equal strengths (i.e., for $\mathrm{CHF}_{3}$ and $\mathrm{CH}_{3} \mathrm{Cl}$ ), the formation of an adsorption monolayer is observed, with the occurrence of traces of multilayer adsorption right before the point of condensation in the case of $\mathrm{CHF}_{3}$, for which the strength of adhesion still slightly exceeds that of cohesion. Finally, in the case of the other adsorbates, for which the cohesive interaction is clearly much stronger than adhesion, no considerable adsorption is seen, as the condensation of these adsorbates well precedes the formation of an adsorption layer of even moderate surface coverage. It is also seen that, at least up to the pressure above which multilayer adsorption occurs, the adsorption isotherm shows a Langmuir character, given that the cohesion is not too strong (i.e., in the case of the partially fluorinated methane derivatives). On the other hand, in accordance with the fact that the Langmuir isotherm assumes, in principle, the complete lack of lateral (i.e., cohesive) interactions, too strong cohesion between the adsorbate molecules leads to the deviation of the isotherm from the Langmuir shape, as seen for $\mathrm{CH}_{3} \mathrm{Cl}$.

It has also turned out that while the strength of the cohesion is determined by the molecular properties of the adsorbates, the strength of the adhesion depends primarily on the possible H-bond formation between the adsorbate and surface water molecules. Our results in this respect show that while the preferred orientation of the $\mathrm{CH}_{3} \mathrm{~F}$ and $\mathrm{CH}_{3} \mathrm{Cl}$ molecules is such that they can form, as $\mathrm{H}$-donors, up to three weak, $\mathrm{C}-\mathrm{H}^{\cdots} \mathrm{O}$-type hydrogen bonds with the surface waters (and, indeed, they both form more than two such H-bonds on average), the $\mathrm{CH}_{2} \mathrm{X}_{2^{-}}$and $\mathrm{CHX}_{3}$-type adsorbates form only one, although stronger, $\mathrm{O}-\mathrm{H}$ donated hydrogen bond as acceptors of the dangling $\mathrm{H}$ atoms of the ice surface. The stronger adsorption of the $\mathrm{CH}_{3} \mathrm{X}$ relative to that of the $\mathrm{CH}_{2} \mathrm{X}_{2}$ and $\mathrm{CHX}$ type molecules clearly shows that, from the point of view of the adsorption, the formation of more, though weaker $\mathrm{H}$-bonds is advantageous over that of one strong H-bond.

From the atmospheric point of view, only the results corresponding to very low surface coverages are of real relevance, as the concentration of these substances in the UTLS region is 
certainly too low not to allow higher surface coverages of the ice grains [37]. However, since these molecules can act as catalysers of certain chemical reactions, such as the decay of ozone, their impact on the atmosphere does not necessarily require their presence in high concentration. Our present results revealed that while partially fluorinated methane derivatives and $\mathrm{CH}_{3} \mathrm{Cl}$ can be expected to be attached to the surface of the ice grains in the troposphere, $\mathrm{CF}_{4}$ and the methane derivatives having more than one chlorine atoms are probably present as isolated molecules in the gas phase. Our results have also revealed that the surface orientation of all these adsorbed molecules is such that at least one of their halogen atoms is exposed to the vapour phase, which makes it easily accessible for reactions with gas phase species, and also easily releasable in photodissociation processes.

\section{Acknowledgements}

This project is supported by the Hungarian OTKA Foundation under project No. 119732, by the Hungarian-French Intergovernmental Science and Technology Program (BALATON) under project No. TéT_15_FR-1-2016-0056, and by CNRS in the framework of an international program for scientific cooperation (PICS).

\section{References}

[1] S. Solomon, R. R. Garcia, F. S. Rowland, D. J. Wuebbles, Nature 321 (1986) 755.

[2] G. J. M. Velders, D. W. Fahey, J. S. Daniel, M. McFarland, O. Andersen, Proc. Natl. Acad. Sci. USA 106 (2009) 10949.

[3] J. P. D. Abbatt, J. L. Thomas, K. Abrahamsson, C. Boxe, A. Granfors, A. E. Jones, M. D. King, A. Saiz-Lopez, P. B. Shepson, J. Sodeau, D. W. Toohay, C. Toubin, R. von Glasow, S. N Wren, X. Yang, Atmos. Chem. Phys. 12 (2012) 6237.

[4] IPCC/TEAP Special Report: Safeguarding the Ozone Layer and the Global Climate System: Issues Related to Hydrofluorocarbons and Perfluorocarbons, Cambridge University Press, Cambridge, 2005. 
[5] R. Hossaini, M. P. Chipperfield, S. A. Montzka, A. Rap, S. Dhomse, W. Feng, Nature Geoscience 8 (2015) 186.

[6] M. M. Hurwitz, E. L. Fleming, P. A. Newman, F. Li, E. Mlawer, K. Cady-Pereira, R. Bailey, Geophys. Res. Lett. 42 (2015) 8686.

[7] Y. D. Lei, F. Wania, Atmos. Environ. 38 (2004) 3557.

[8] F. Dominé, P. B. Shepson, Science 297 (2002) 1506.

[9] A. M. Grannas, A. E. Jones, J. Dibb, M. Ammann, C. Anastasio, H. J. Beine, M. Bergin, J. Bottenheim, C. S. Boxe, G. Carver, G. Chen, J. H. Crawford, F. Dominé, M. M. Frey, M. I. Guzmán, D. E. Heard, D. Helmig, M. R. Hoffmann, R. E. Honrath, L. G. Huey, M. Hutterli, H. W. Jacobi, P. Klán, B. Lefer, J. McConnell, J. Plane, R. Sander, J. Savarino, P. B. Shepson, W. R. Simpson, J. R. Sodeau, R. von Glasow, R. Weller, E. W. Wolff, T. Zhu, Atmos. Chem. Phys. 7 (2007) 4329.

[10] J .P. D. Abbatt, Chem. Rev. 103 (2003) 4783.

[11] T. Huthwelker, M. Ammann, T. Peter, Chem. Rev. 106 (2006) 1375.

[12] T. Bartels-Rausch, H. W. Jacobi, T. F. Kahan, J. L. Thomas, E. S. Thomson, J .P. D. Abbatt, M. Ammann, J. R. Blackford, H. Bluhm, C. Boxe, F. Domine, M. M. Frey, I. Gladich, M. I. Guzmán, D. Heger, T. Huthwelker, P. Klán, W. F. Kuhs, M. H. Kuo, S. Maus, S. G. Moussa, V. F. McNeill, J. T. Newberg, J. B. C. Pettersson, M. Roeselová, J. R. Sodeau, Atmos. Chem. Phys. 14 (2014) 1587.

[13] J. N. Crowley, M. Ammann, R. A. Cox, R. G. Hynes, M. E. Jenkin, A. Mellouki, M. J. Rossi, J. Troe, T. J. Wallington, Atmos. Chem. Phys. 10 (2010) 9059.

[14] M. Moreno, A. Aranda, Y. Díaz-de-Mera, E. Martínez, I. Bravo, A. Rodríguez, Phys. Chem. Chem. Phys. 14 (2012) 4425.

[15] J. Blanchard, J. T. Roberts, Langmuir 10 (1994) 3303.

[16] V. Sadtchenko, K. Knutsen, C. F. Giese, W. Ronald Gentry, J. Phys. Chem. B 104 (2000) 2511.

[17] V. Sadtchenko, K. Knutsen, C. F. Giese, W. Ronald Gentry, J. Phys. Chem. B 104 (2000) 4894.

[18] V. Buch, L. Delzeit, C. Blackledge, J. P. Devlin, J. Phys. Chem. 100 (1996) 3732.

[19] C. Martin, C. Manca, P. Roubin, Surf. Sci. 502-503 (2002) 275.

[20] A. P. Graham, A. Menzel, J. P. Toennies, J. Chem. Phys. 111 (1999) 1169. 
[21] N. S. Holmes, J. R. Sodeau, J. Phys. Chem. A 103 (1999) 4673.

[22] K. Harper, B. Minofar, M. N. Sierra-Hernandez, N. N. Casillas-Ituarte, M. Roeselova, H. C. Allen, J. Phys. Chem. A 113 (2009) 2015.

[23] T. A. Vysokikh, D. F. Mukhamedzyanova, T. V. Yagodovskaya, S. V. Savilov, V. V. Lunin, Russian J. Phys. Chem. A 81 (2007) 1836.

[24] J. E. Schaff, J. T. Roberts, Surf. Sci. 426 (1999) 384.

[25] M. L. Greca, E. H. G. Backus, H. J. Fraser, T. Pradeep, A. W. Kleyn, M. Bonn, Chem. Phys. Letters 385 (2004) 244.

[26] M. Aoki, Y. Ohashi, S. Masuda, Surf. Sci. 532-535 (2003) 137.

[27] A. Pysanenko, A. Habartová, P. Svrčková, J. Lengyel, V. Poterya, M. Roeselová, J. Fedor, M. Fárnik, J. Phys. Chem. A 119 (2015) 8991.

[28] J. Cyriac, T. Pradeep J. Phys. Chem. C 111 (2007) 8557.

[29] M. P. Allen, D. J. Tildesley, Computer Simulation of Liquids, Clarendon, Oxford, 1987.

[30] S. Picaud, P. N. M. Hoang, Phys. Chem. Chem. Phys. 6 (2004) 1970.

[31] L. B. Pártay, P. Jedlovszky, P. N. M. Hoang, S. Picaud, M. Mezei, J. Phys. Chem. C 111 (2007) 9407.

[32] A. Habartová, K. T. Valsaraj, M. Roeselová, J. Phys. Chem. A 117 (2013) 9205.

[33] A. Habartová, L. Hormain, E. Pluhařová, S. Briquez, M. Monnerville, C. Toubin, M. Roeselová, J. Phys. Chem. A 119 (2015) 10052.

[34] D. J. Adams, Mol. Phys. 20 (1975) 307.

[35] I. Sumi, S. Picaud, P. Jedlovszky, J. Phys. Chem. C 119 (2015) 17243.

[36] I. Sumi, B. Fábián, S. Picaud, P. Jedlovszky, J. Phys. Chem. C 120 (2016) 17243.

[37] I. Sumi, S. Picaud, P. Jedlovszky, J. Phys. Chem. C, in press.

[38] C. G. Gray, K. E. Gubbins, Theory of Molecular Fluids. Volume 1: Fundamentals. Clarendon Press, Oxford, 1984, Appendix D.

[39] D. R. Lide (Ed.), CRC Handbook of Chemistry and Physics, $78^{\text {th }}$ Edition, CRC Press, Boca Raton, 1997-1998.

[40] P. Tremaine, M. G. Robinson, Can. J. Chem. 51 (1973)1497.

[41] M. Mahoney, W. L. Jorgensen, J. Chem. Phys. 112 (2000) 8910.

[42] H. Nada, J. P. M. J.van der Eerden, J. Chem. Phys. 118 (2003) 7401. 
[43] C. Vega, E. Sanz, J. L. F. Abascal, J. Chem. Phys. 122 (2005) 114507.

[44] B. J. Palmer, J. L. Anchell, J. Phys. Chem. 99(1995) 12239.

[45] P. Jedlovszky, M. Mezei, J. Chem. Phys. 110 (1999) 2991.

[46] J. Wang, R. M. Wolf, J. W. Caldwell, P. A. Kollmann, D. A. Case, J. Comp. Chem. 25 (2004) 1157.

[47] M. W. Evans, M. Ferrario, Adv. Molec. Rel. Int. Proc. 22 (1982) 245.

[48] G. R. Kneller, A. Geiger, Mol. Phys. 68 (1989) 487.

[49] W. Dietz, K. Heinzinger, Ber. Bunsenges. Phys. Chem. 88 (1984) 543.

[50] E. M. Duffy, D. L. Severance, W. L. Jorgensen, J. Am. Chem. Soc. 114 (1992) 7535.

[51] J. Chandrasekhar, S. F. Smith, W. L. Jorgensen, J. Am. Chem. Soc. 107 (1985) 154.

[52] W. L. Jorgensen, J. M. Briggs, M. Leonor Contreras, J. Phys. Chem. 94 (1990) 1683.

[53] M. Mezei, MMC: Monte Carlo Program for Simulation of Molecular Assemblies. URL: http://inka.mssm.edu/ mezei/mmc.

[54] D. H. Everett, Pure Appl. Chem. 31 (1972) 577.

[55] A. C. Mitropoulos, J. Eng. Science Technol. Review 1 (2008) 1.

[56] C. D. Daub, G. N. Patey, D. B. Jack, A. K. Sallabi, J. Chem. Phys. 124 (2006) 114706.

[57] B. Widom, in: C. Domb, M. S. Green (Eds.), Phase Transitions and Critical Phenomena, Vol. 2, Academic Press, Cambridge, 1972.

[58] G. G. Simeoni, T. Bryk, F. A. Gorelli, M. Krisch, G. Ruocco, M. Santoro, T. Scopigno, Nature Physics 6 (2010) 503.

[59] I. Langmuir, J. Am. Chem. Soc. 38 (1916) 2221.

[60] D. J. Shaw, Introduction to Colloid and Surface Chemistry, Butterworths, London, 1980.

[61] P. Jedlovszky, Á. Vincze, G. Horvai, J. Chem. Phys. 117 (2002) 2271.

[62] P. Jedlovszky, Á. Vincze, G. Horvai, Phys. Chem. Chem. Phys. 6 (2004) 1874.

[63] P. Jedlovszky, L. Pártay, P. N. M. Hoang, S. Picaud, P. von Hessberg, J. N. Crowley, J. Am. Chem. Soc. 128 (2006) 15300.

[64] Mukhopadhyay, A. Comput. Theor. Chem. 1083 (2016) 19.

[65] P. Jedlovszky, L. Turi, J. Phys. Chem. B 101 (1997) 5429. 


\section{Tables}

Table 1. Experimental properties of the adsorbates studied. $M, d, \varepsilon, T_{\mathrm{b}}$ and $T_{\text {crit }}$ stand for the molar mass, dipole moment of the isolated molecule, dielectric constant, boiling temperature (at atmospheric pressure), and critical temperature, respectively.

\begin{tabular}{cccccc}
\hline Compound & $M / \mathrm{g} \mathrm{mol}^{-1}$ & $d / \mathrm{D}$ & $\varepsilon^{\mathrm{b}}$ & $T_{\mathrm{b}} / \mathrm{K}$ & $T_{\text {crit }} / \mathrm{K}$ \\
\hline $\mathrm{CH}_{4}$ & 16.04 & 0 & $1.7^{\mathrm{c}}$ & $111.6^{\mathrm{c}}$ & $190.6^{\mathrm{c}}$ \\
$\mathrm{CH}_{3} \mathrm{~F}$ & 34.03 & $1.85^{\mathrm{a}}$ & $25.1^{\mathrm{d}}$ & $194.7^{\mathrm{c}}$ & $317.8^{\mathrm{c}}$ \\
$\mathrm{CH}_{2} \mathrm{~F}_{2}$ & 52.02 & $1.98^{\mathrm{a}}$ & $26.1^{\mathrm{d}}$ & $221.5^{\mathrm{c}}$ & $351.6^{\mathrm{c}}$ \\
$\mathrm{CHF}_{3}$ & 70.01 & $1.65^{\mathrm{a}}$ & $19.8^{\mathrm{d}}$ & $191.0^{\mathrm{c}}$ & $299.3^{\mathrm{c}}$ \\
$\mathrm{CF}_{4}$ & 88.00 & 0 & $1.6^{\mathrm{d}}$ & $145.1^{\mathrm{c}}$ & $227.6^{\mathrm{c}}$ \\
$\mathrm{CH}_{3} \mathrm{Cl}$ & 50.49 & $1.90^{\mathrm{a}}$ & $13.1^{\mathrm{c}}$ & $249.1^{\mathrm{c}}$ & $416.3^{\mathrm{c}}$ \\
$\mathrm{CH}_{2} \mathrm{Cl}_{2}$ & 84.93 & $1.60^{\mathrm{a}}$ & $8.4^{\mathrm{c}}$ & $313.1^{\mathrm{c}}$ & $510.0^{\mathrm{c}}$ \\
$\mathrm{CHCl}_{3}$ & 119.38 & $1.04^{\mathrm{a}}$ & $4.2^{\mathrm{c}}$ & $334.2^{\mathrm{c}}$ & $536.4^{\mathrm{c}}$ \\
$\mathrm{CCl}_{4}$ & 153.82 & 0 & $2.1^{\mathrm{c}}$ & $349.9^{\mathrm{c}}$ & $556.6^{\mathrm{c}}$ \\
\hline \hline
\end{tabular}

\footnotetext{
${ }^{a}$ Ref. [38]

${ }^{b}$ Measured in the liquid phase, right below the boiling temperature.

${ }^{\mathrm{c}}$ Ref. [39]

${ }^{\mathrm{d}}$ Ref. [40]
} 
Table 2. Calculated energetic properties characterising the adsorption of the nine adsorbates considered (in $\mathrm{kJ} / \mathrm{mol}$ units). For the exact meaning of the different quantities, we refer the reader to the text.

\begin{tabular}{ccccc}
\hline \hline Adsorbate & $\mu_{\text {start }}$ & $\mu_{0}$ & $\left\langle U_{\text {low }}^{\text {ice }}\right\rangle$ & $\left\langle U_{\text {cond }}^{\text {lat }}\right\rangle$ \\
\hline $\mathrm{CH}_{4}$ & -25.3 & -16.75 & -4.4 & -8.6 \\
$\mathrm{CH}_{3} \mathrm{~F}$ & -44.0 & -25.09 & -28.8 & -21.6 \\
$\mathrm{CH}_{2} \mathrm{~F}_{2}$ & -40.2 & -24.43 & -26.7 & -23.7 \\
$\mathrm{CHF}_{3}$ & -43.8 & -30.48 & -30.5 & -29.7 \\
$\mathrm{CF}_{4}$ & -31.3 & -24.55 & -6.9 & -15.3 \\
$\mathrm{CH}_{3} \mathrm{Cl}$ & -50.0 & -36.29 & -40.3 & -42.3 \\
$\mathrm{CH}_{2} \mathrm{Cl}_{2}$ & -38.6 & -35.13 & -19.8 & -40.5 \\
$\mathrm{CHCl}_{3}$ & -40.0 & -37.85 & -20.5 & -46.9 \\
$\mathrm{CCl}_{4}$ & -37.3 & -36.41 & -12.4 & -49.0 \\
\hline \hline
\end{tabular}




\section{Figures Legend}

Fig. 1. Mean number of adsorbate molecules in the basic simulation box as a function of the chemical potential, as obtained from the sets of GCMC simulations of the nine adsorbate molecules considered. Top panel, filled symbols: fluorinated methane derivatives, bottom panel, open symbols: chlorinated methane derivatives. The data corresponding to $\mathrm{CH}_{4}$ is shown in both panels (black asterisks). Red circles: $\mathrm{CH}_{3} \mathrm{X}$ molecules, green squares: $\mathrm{CH}_{2} \mathrm{X}_{2}$ molecules, orange down triangles: $\mathrm{CHX}_{3}$ molecules, blue up triangles: $\mathrm{CX}_{4}$ molecules $(\mathrm{X}$ stands for $\mathrm{F}$ or $\mathrm{Cl}$ ). The lines connecting the points are just guides to the eye.

Fig. 2. (a) Average lateral interaction energy of an adsorbate molecule, being in contact with the ice phase, in the presence of the condensed phase of the adsorbate, plotted against the chemical potential corresponding to the point of condensation, $\mu_{0}$, and (b) average interaction energy of an adsorbate molecule with the ice phase at very low surface coverage, plotted against the chemical potential at which the number of adsorbed molecules becomes noticeably different from zero, $\mu_{\text {start, }}$ as obtained for the nine adsorbates considered. For the exact definition of these quantities, see the text. The inset shows the obtained $\mu_{0}$ values against the experimental boiling temperature of these molecules. Asterisk: $\mathrm{CH}_{4}$, blue filled circles: fluorinated methane derivatives, red open circles: chlorinated methane derivatives.

Fig. 3. Adsorption isotherms (in the $\Gamma$ vs $p_{\text {rel }}$ form) of the nine adsorbate molecules considered. Top panel, filled symbols: fluorinated methane derivatives, bottom panel, open symbols: chlorinated methane derivatives. The thick dashed lines show the Langmuir isotherms fitted to the low pressure part of the $\mathrm{CH}_{3} \mathrm{~F}, \mathrm{CH}_{2} \mathrm{~F}_{2}$, and $\mathrm{CHF}_{3}$ isotherms. The data corresponding to the $\mathrm{CH}_{4}$ isotherm is shown in both panels (black asterisks). Red circles: $\mathrm{CH}_{3} \mathrm{X}$ molecules, green squares: $\mathrm{CH}_{2} \mathrm{X}_{2}$ molecules, orange down triangles: $\mathrm{CHX}_{3}$ molecules, blue up triangles: $\mathrm{CX}_{4}$ molecules ( $\mathrm{X}$ stands for $\mathrm{F}$ or $\mathrm{Cl}$ ). The inset shows the isotherms of $\mathrm{CH}_{2} \mathrm{Cl}_{2}, \mathrm{CHCl}_{3}$, and $\mathrm{CCl}_{4}$ on a magnified scale. The lines connecting the points are just guides to the eye. 
Fig. 4. Definition of the local Cartesian frame fixed to the individual (a) $\mathrm{CX}_{3} \mathrm{Y}$ type, and (b) $\mathrm{CH}_{2} \mathrm{X}_{2}$ type adsorbate molecules in the orientational analysis, and that of the polar angles, $\vartheta$ and $\phi$, of the surface normal vector, $\underline{X}$, pointing, by our convention, away from the ice surface, in these frames.

Fig. 5. Orientational maps of the $\mathrm{CH}_{3} \mathrm{X}$ (left) and $\mathrm{CHX}_{3}$ (right) type adsorbates (X stands for $\mathrm{F}$ or $\mathrm{Cl}$ ) that are in contact with the ice phase at very low surface coverage (top row) and in the presence of the condensed phase of the adsorbate (bottom row). Lighter shades of grey correspond to higher probabilities. The preferred orientations of the adsorbate molecules are also illustrated; $\mathrm{C}, \mathrm{H}$, and halogen atoms are shown by grey, white, and green balls, respectively. $\underline{X}$ is the surface normal vector pointing away from the ice phase.

Fig. 6. Orientational maps of the $\mathrm{CH}_{2} \mathrm{X}_{2}$ type adsorbates ( $\mathrm{X}$ stands for $\mathrm{F}$ or $\mathrm{Cl}$ ) that are in contact with the ice phase at very low surface coverage (top row) and in the presence of the condensed phase of the adsorbate (bottom row). Lighter shades of grey correspond to higher probabilities. The preferred orientations of the adsorbate molecules are also illustrated; $\mathrm{C}, \mathrm{H}$, and halogen atoms are shown by grey, white, and green balls, respectively. $\underline{X}$ is the surface normal vector pointing away from the ice phase.

Fig. 7. Illustration of the possible hydrogen bonding arrangements of the $\mathrm{CH}_{3} \mathrm{X}$ type (top row), $\mathrm{CHX}_{3}$ type (middle row), and $\mathrm{CH}_{2} \mathrm{X}_{2}$ type (bottom row) adsorbate molecules with surface waters, in which both molecules are aligned in one of their preferred orientations. $\mathrm{O}, \mathrm{C}, \mathrm{H}$, and halogen atoms are shown by red, grey, white, and green balls, respectively. $\underline{X}$ is the surface normal vector pointing away from the ice phase. The inset (top left) shows the four preferred orientations of the water molecules at the ice surface [!63]. 
Figure 1

Sumi et al.

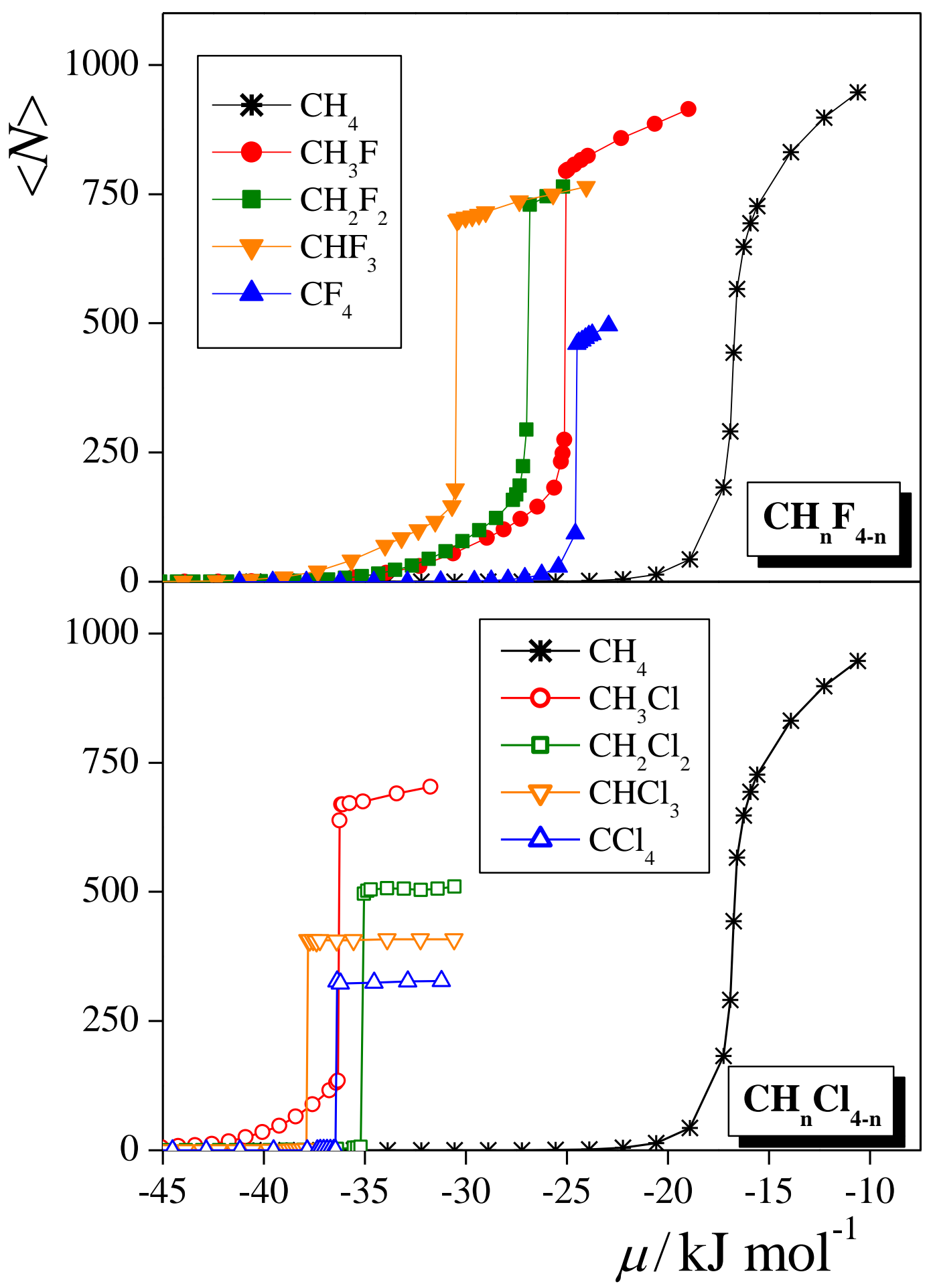


Figure 2

Sumi et al.

(a)

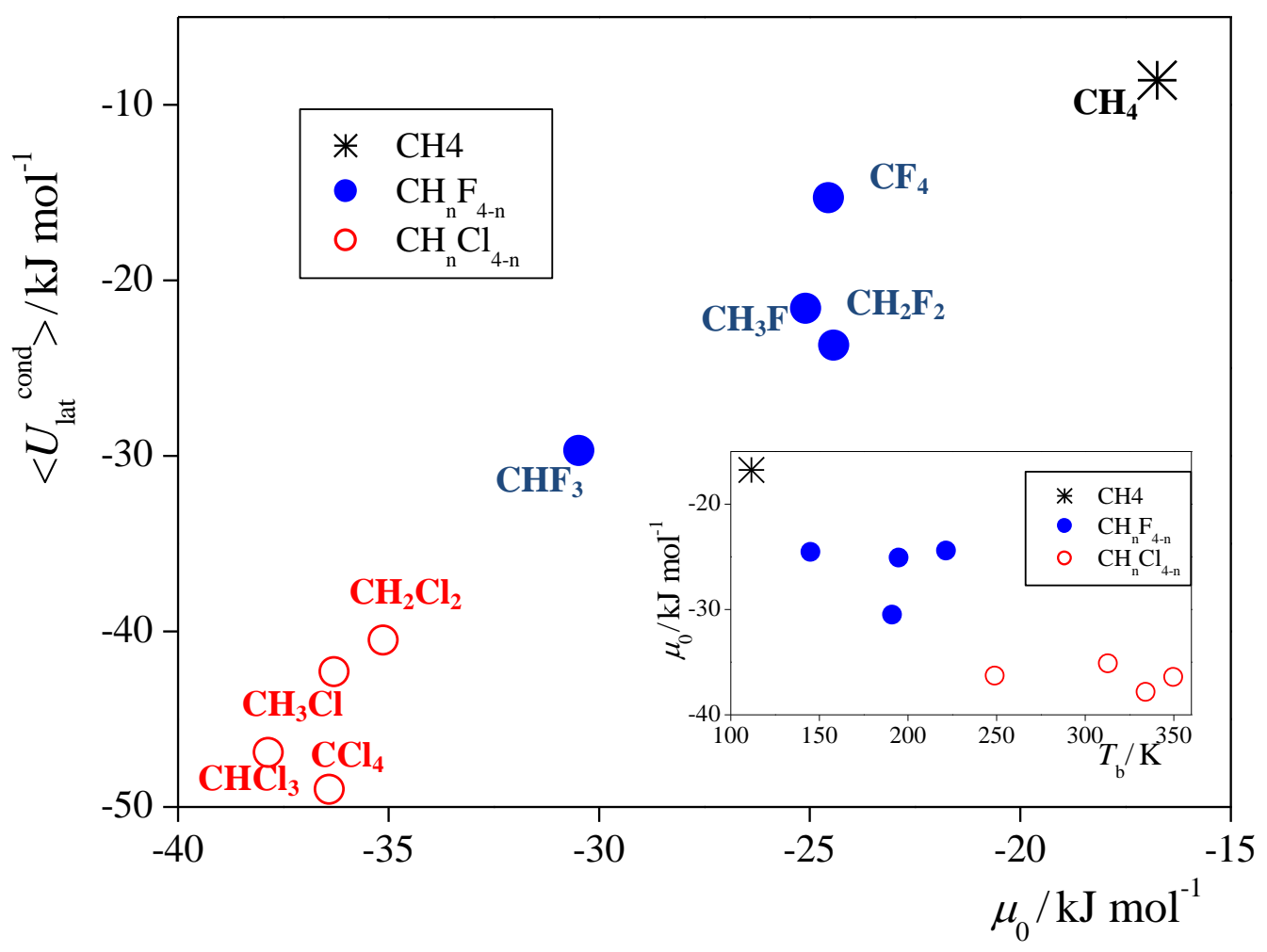

(b)

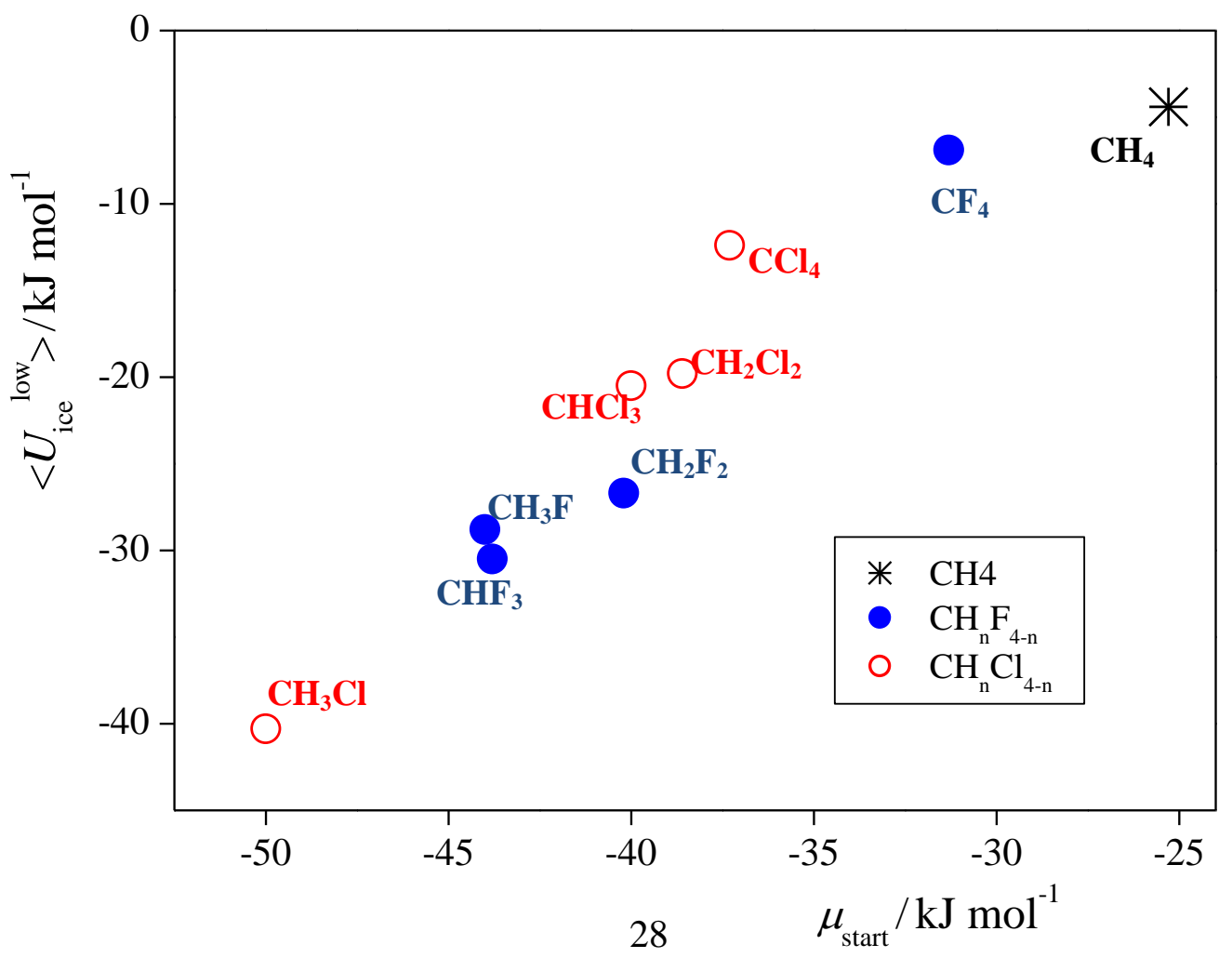


Figure 3

Sumi et al.

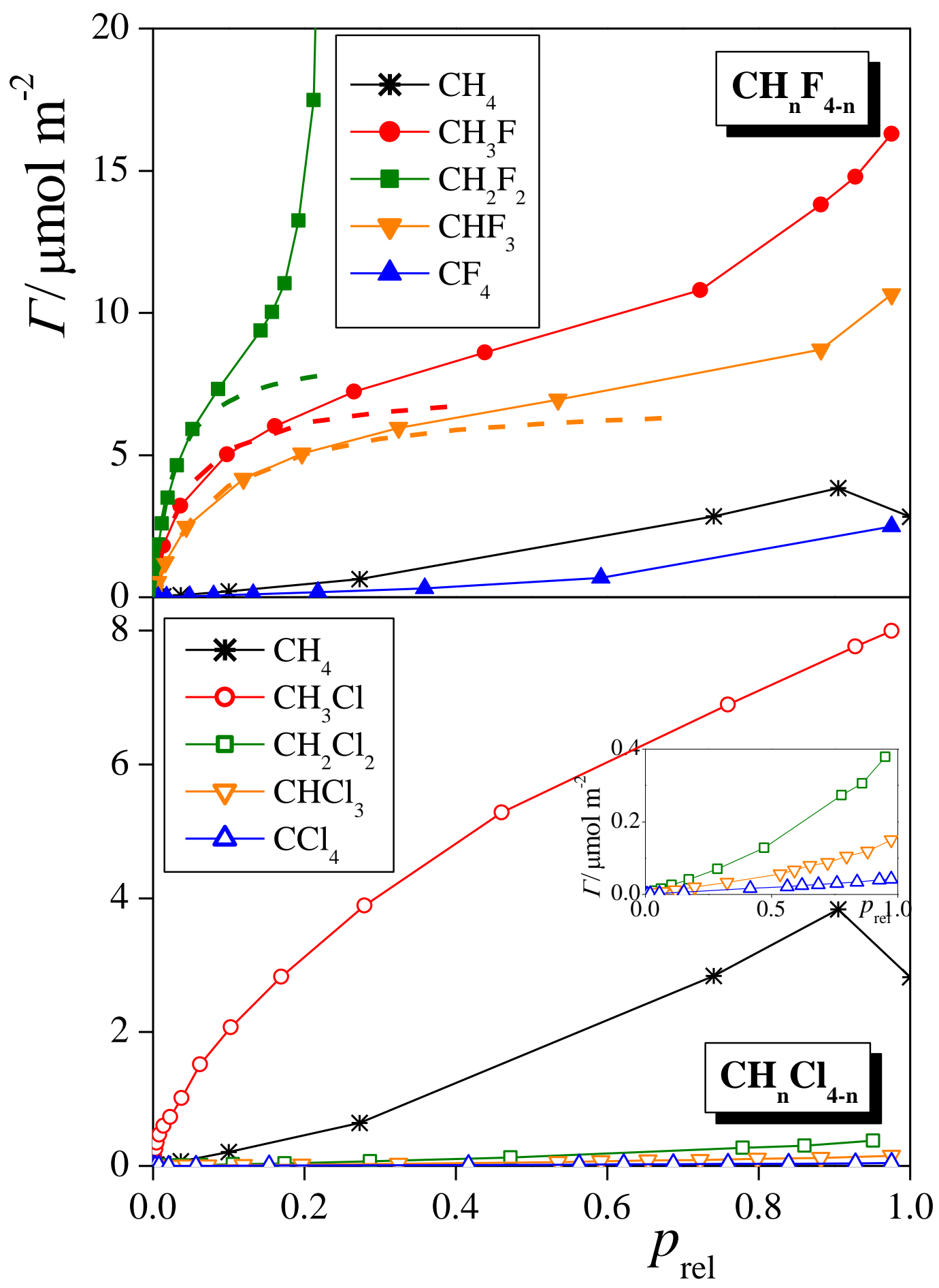


Figure 4

Sumi et al.
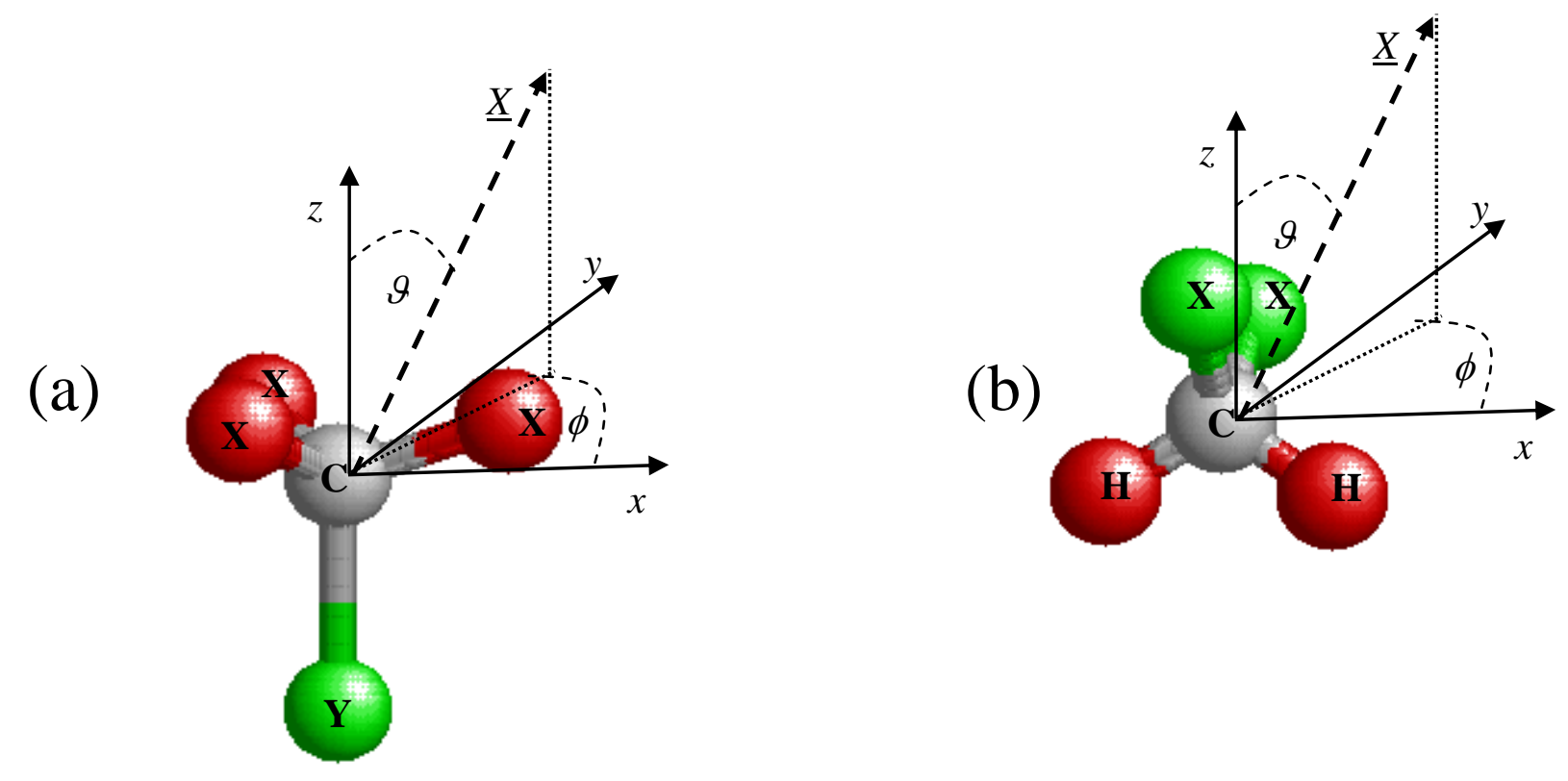
Figure 5

Sumi et al.
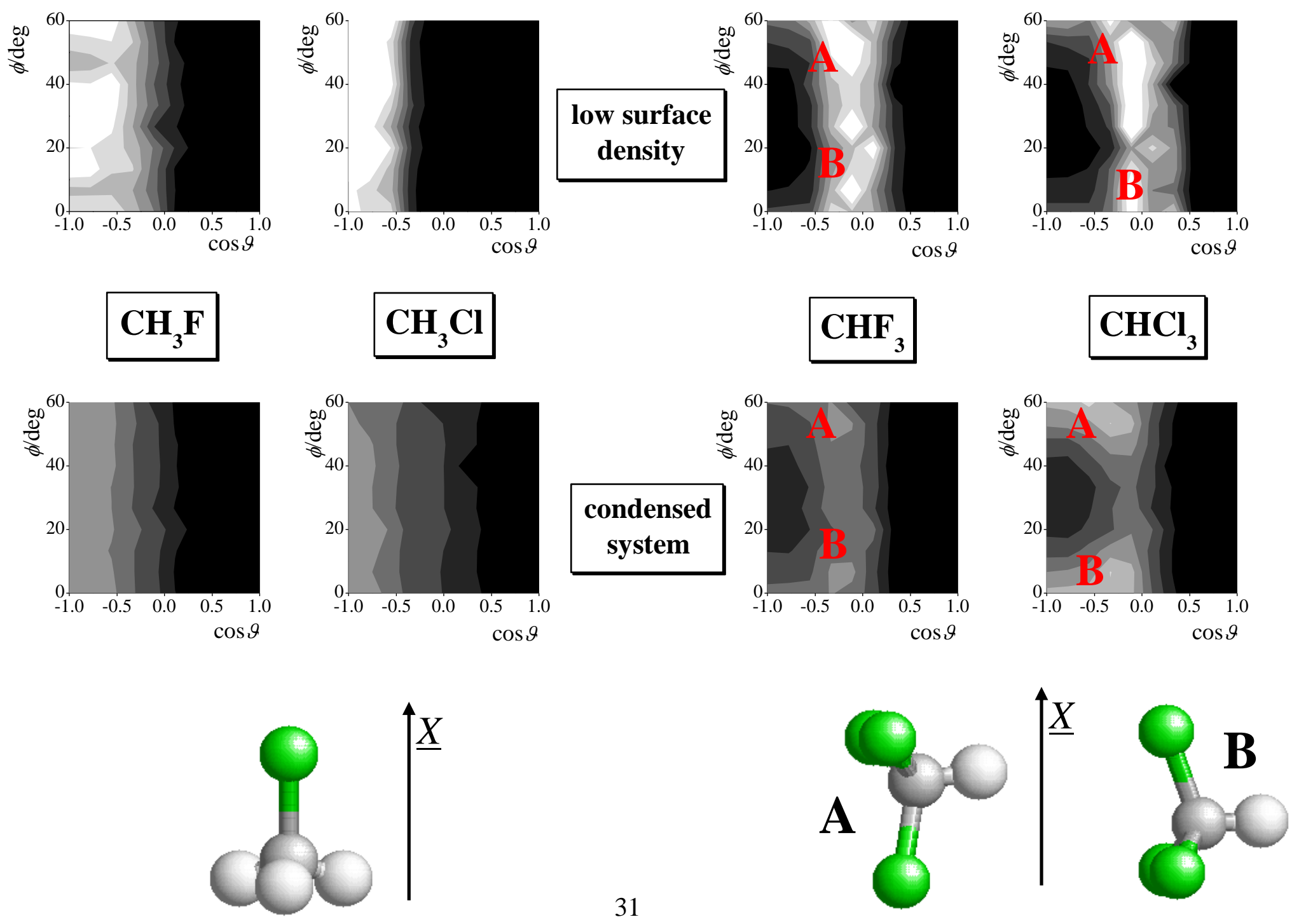
Figure 6

Sumi et al.
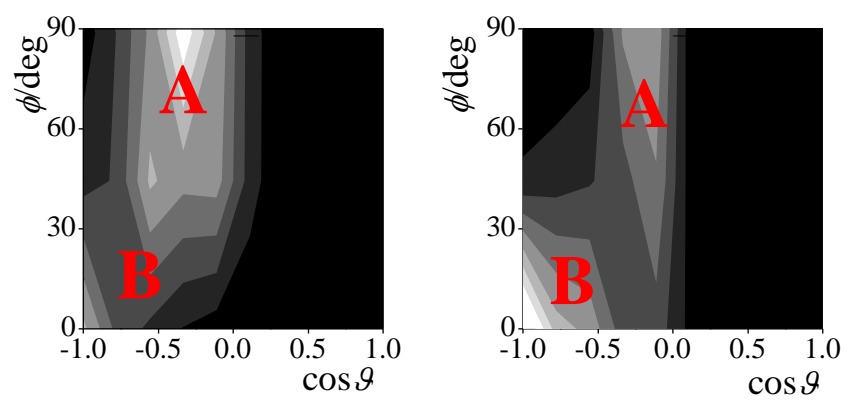

low surface density

\section{$\mathrm{CH}_{2} \mathrm{~F}_{2}$}

\section{$\mathrm{CH}_{2} \mathrm{Cl}_{2}$}
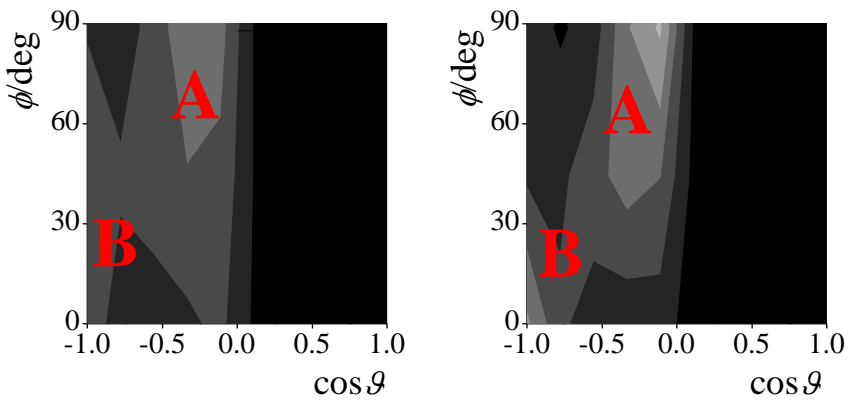

condensed

system
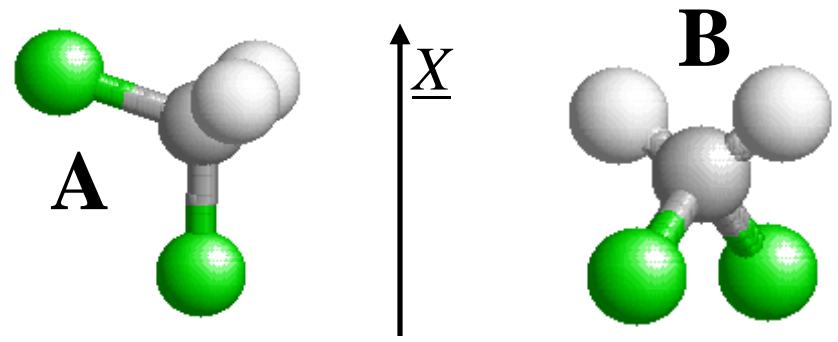
Figure 7

Sumi et al.
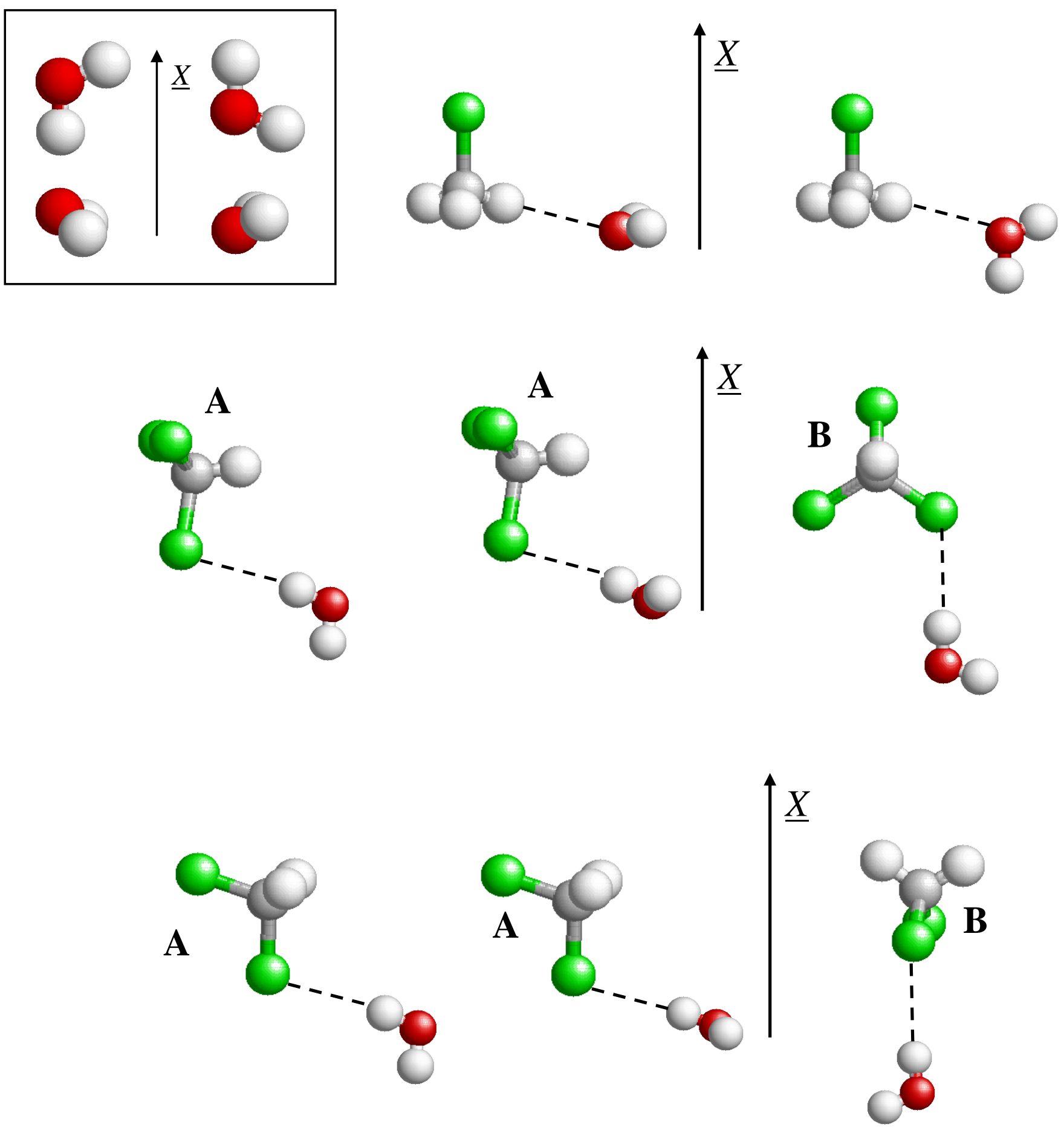